the same time.

As the author says, old age only emerged as an issue for central government in the late 19th century and it was viewed then in straightforward negative terms as a social problem. Now, with demographic changes, the elderly form a much larger and increasingly vociferous group.

British textbooks on the views of the elderly are thin on the ground and one based on Aberdeen is unique. As such it forms a valuable contribution to the field and will be of much interest to social gerontologists and also perhaps to those in the political field and among the caring professions who seek to understand the elderly's perspective. It should make a useful and unique addition to many libraries.

MALCOLM MACARTHUR, Department of Medicine for the Elderly, Woodend Hospital, Aberdeen.

\section{Medical Choices: Medical Chances}

Harold Bursztajn, Richard I Feinbloom, Robert $M$ Hamm, Archie Brodsky, 454 pages, New York and London, 1990, Routledge, £12.99.

This book modestly aims to change the way those involved in clinical situations look at the world and it is difficult to do its breadth of vision justice in a short review. Its central thesis is that too many medical decisions are made under the influence of mechanistic determinism which teaches us to look for the cause or set of causes for every effect. Given enough time we can track down the formula, and from then on it will always be true that merely by changing cause $x$ we can prevent effect y. The paradigm promises a comforting certainty and predictability and therefore has tremendous psychological appeal for patients and clinicians alike.

The authors seek to persuade us that, even though we will have on occasions, to fall back on determinism, medicine should look to the more fruitful probabilistic paradigm and the ideas of Heisenberg and chaos theorists. Life is uncertain. We cannot ignore that uncertainty if we are to make decisions which are both realistic and ethical. Medical decisions can be seen as a form of co-operative and morally-responsible gambling. By facing up to uncertainty there is a better chance of achieving a good outcome on more occasions.

To overcome the reader's likely resistance to these unsettling propositions the authors employ an extremely effective literary device. In chapter 1 we meet $\mathrm{Dr} S$ as he considers how to treat a severely malnourished child whose underlying illness defies risk-free diagnosis. Dr $S$ decides to concentrate on the nourishment problem. The child begins to make progress. One day, when Dr $S$ is off duty, well-meaning mechanist colleagues switch on the hospital diagnostic machine, which is programmed to identify objectively knowable biological facts. Eventually the child dies, perhaps quite literally tested to death in the effort to spare no effort to save him.

We then share the experience of $\operatorname{Dr} S$ as he tries to make sense of this tragic incident and to find his way through a maze of well-described medical scenarios under the growing influence of the probabilistic paradigm. The moral and intellectual issues are complex but the device of $\mathrm{Dr} S$ makes the pace manageable. The reader is encouraged to think for himself but is not expected to undergo a Damascene conversion. The disciplinary breadth of the team behind this book is enriching and makes it extremely accessible for those with no medical knowledge or clinical experience. On the minus side, Dr S might grate a little by the end of his 'confession of a mechanist doctor'. There is just the faintest whiff of the smugness of the confessional.

There are, of course, more serious criticisms that might be made of this book. Endemic uncertainty and medical accountability do not make very comfortable bedfellows and the tension between them is not satisfactorily addressed. Nor is the tension fully explored between the highly recommended involvement of family and friends of the patient and autonomy and confidentiality. It is difficult to reconcile a belief in moral absolutes or religion with such a scheme of thinking.

This book does not explore concepts of autonomy or euthanasia as such, but is rather directed at the underlying philosophical concepts of knowledge and wisdom and their effect on our ability to make valid moral judgements. It is a fascinating and challenging attempt to wean us off scientific objectivism and to convince us that in an uncertain world it is a morally dubious practice to behave as if certainty is guaranteed. London WCIR $4 H E$.

\section{Why Should We Care?}

Edited by Donald Evans, vii +152 pages, London, 1990, Macmillan, $£ 10.95 \mathrm{pb}$.

We have been taught that the unexamined life is not worth living but there is a real question as to whether, for most of us, the fully-examined life is liveable. Socrates criticised the Sophists for inducing an unreflective conventionalism among the Athenians but the dialogues often show how the effect of his persistent questioning was simply to disable his discussants. A recognition of one's existing ignorance may be a necessary condition for advancement to wisdom but it is clearly not sufficient for it; and in matters moral it is a debated question whether there is anything to be wise about.

Such thoughts are apt to arise in anyone who has been involved in getting non-philosophers to think about the ethical presuppositions of conduct. There is no end of occasions for wondering how best to act, and it is to be expected that reflective minds will turn in a philosophical direction in search of, if not answers, then at least: methods of enquiry, analysis and resolution. Philosophers also have an interest in promoting ethical enquiries. Such interest may be professional or 'professional', but either way there is a responsibility not to create expectations that cannot be satisfied.

Why should doctors, nurses and therapists care about their patients? The answer is obvious: because it is of the nature of these professions to do so. Where primary human values are engaged, practitioners have a commitment to promote or defend them. For such people, caring is not an optional extra but a professional duty. The same analytical point is made in different ways throughout this collection, as is the barely less obvious point that moral issues, for whose resolution medical competence is not as such a qualification, are ever present. Sometimes, though, the point is overstated: it is not entailed by the very nature of choice that whenever there is more than one alternative that can be followed, the decision will be a moral one. At least, that is not implied by common-sense morality which allows for 'moral-free zones' and decisions. Utilitarianism, of course, does suggest the inescapability of the moral, but as many of the contributors point out, such a theory faces considerable 
problems; it also undermines the earlier idea of special duties of care attaching to health workers.

These essays range over a familiar set of questions: abortion, euthanasia, autonomy, consent, resource allocation and testing, and vary in length (from 7 to 20 pages) and degree of philosophical sophistication. They have nothing to add in the way of reflective understanding of these issues, but are not redundant on that account, for having been written largely by health care professionals, they are, perhaps, more likely to engage the interest of similar readers than are 'applied' works by professional philosophers. The two longest and most extensively referenced essays are by the same author, Richard Bentall, on Values and Diagnosis and Compulsory Care. In the briefest contribution, Should My Baby Live?, Sylvia Parker movingly and effectively places a moral dilemma within a context of philosophical theories, thereby showing the complexity of the issue and the foolishness of the assumption that going 'philosophical' means finding a decision procedure.

There is a growing need for informed reflection on the ethics of health care which manages to achieve understanding while avoiding the incapacitating effect of abstract speculation. That need is most likely to be met by thoughtful practitioners such as the contributors to this collection. Deeper and wiser thinking is necessary but this is a good start to an ongoing series of publications.

JOHN HALDANE, Reader in Moral Philosophy, Director of the Centre for Philosophy and Public Affairs, University of St Andrews.

\section{Health Promotion: Models and Values}

\author{
R S Downie, Carol Fyfe, Andrew \\ Tannahill, 183 pages, Oxford, 1990, \\ Oxford Medical Publications, \\ $£ 25.00 \mathrm{hc}, £ 12.95 \mathrm{sc}$.
}

What makes health promotion worth doing? On which goals should health promoters set their sights? What's health promotion for? To outsiders these must seem peculiar questions. After all most professions know what their purposes are. It would be a contradiction in terms for a lawyer, or a bank manager, or an accountant to say:
'I do not understand the rationale of my work'. Nonetheless, strange as it will appear to the uninitiated, one of the central characteristics of the caring professions is massive uncertainty about basic principles and direction.

In highlighting this area of doubt, and in identifying such clear key questions, Robin Downie and his colleagues have done health promotion a great service. There is, amongst many health promoters, deep unease that 'something's wrong'. A considerable number of practitioners are perturbed that their role is unclear, and that crucial underlying questions are left untouched. The prevailing emphasis is on function, on doing, on performing, but nobody has yet properly asked: 'Why this function rather than that one?'. In other words no one has tackled the philosophy of health promotion.

Unfortunately, frustrated health promoters must wait a little longer. Despite defining the right area of study the authors fail to deliver the goods. The book is a prescription for 'good practice' rather than a dispassionate philosophical review. It quickly becomes a crusade for an authoritarian approach to health promotion. As such it is a clear exposition of the values and aims of this sort of health promotion, but it does not seriously examine the critical key questions.

The argument is that there are 'better and worse life-styles', and that the point of health promotion activity is to ensure that the 'better' life-styles flourish. This point of view is reinforced by another: that it is possible to distinguish between 'subjective' and 'objective' well-being. 'Subjective' well-being is not necessarily 'true' well-being. Even if an individual 'feels great for a lifetime' his or her well-being may be 'spurious' if it 'arises from influences which are overall detrimental to an individual's functioning or flourishing, and/or to society'.

The authors make few bones about their position, and are quite open about their preferences for 'the good life'. For example, they argue that antidepressants induce 'subjective' wellbeing, whereas financial and other social support for a depressed person can promote 'objective' well-being through the provision of life-skills. Most targets for 'health promoters' derived from medical priorities are accepted without question: smoking is bad, drinking too much is bad, avoiding immunisation is bad. In a passage which reveals much about the aims of the book, and the level of some of the debate, the authors pour scorn on the 'non-judgemental' approach to health promotion. They quote an earlier writing partnership on the topic, Linda Ewles and Ina Simnett:

In discussing the inadequacies of traditional health education they (Ewles and Simnett) state that it has sometimes involved (among other failings):

".. the imposition of medical values on the client. Frequently, this means the imposition of middle-class values on working-class people, and the ethical justification for this is doubtful. For example, losing weight and lowering blood pressure may be the most important thing to a doctor, but drinking beer in the pub with friends may be far more important to his overweight, middle-aged, unemployed patient. Who is to say which set of values is 'right' - the doctor or his patient? Whose life is it anyway?"

'Two points can be made here. First, if the client wants to lose weight then he ought to take the doctor's advice and cut down on his beer drinking. Otherwise, why consult the doctor at all? Secondly, the health promoter is presumably committed to believing that health is at least one important value, and so is alsocommitted to believing that the clien should take the doctor's advice.'

But it is pretty clear that the man in the excerpt from Ewles has not gone to the doctor about his weight, and that he does not wish to have or take the doctor's advice on the matter. Much worse, 'health' is not a single value, as the authors themselves point out earlier. Nor is it true, even if health were a single value, that a belief that health is a good thing necessarily means that a person should take medical advice, or will achieve 'health' if he or she does. Medical work is not always work for health, as countless sociological and philosophical studies have shown.

Health Promotion: Models and Values is a disappointment. Time after time it raises fascinating questions, yet consistently fails to give them the depth of attention they deserve. The book acknowledges that there are different approaches to health promotion, opts for one only, and then shouts rather than argues for it. What is required, for an insightful philosophical investigation into health promotion (which is now needed more than ever), is the 'bird's eye view' promised in the publisher's blurb, not a campaign from within. 